\title{
EXTRA SLIP OF LATISSIMUS DORSI TENDON AND ITS CLINICAL SIGNIFICANCE
}

Ritwik Baidya ${ }^{1}$, Sushil Kumar $* 2$.

${ }^{1}$ Assistant professor, Anatomy division, Department of radiology, Weill Cornell Medicine, New York.

${ }^{* 2}$ Assistant professor, Anatomy division, Department of radiology, Weill Cornell Medicine, New York.

\section{ABSTRACT}

A typical muscle variation of latissimus dorsi is observed during routine dissection in the anatomy lab. A fibromuscular slip detached from the anteroinferior border of the muscle cross the brachial plexus and axillary vessels and inserts with the pectoralis major on the lateral lip of the intertubercular sulcus.

KEY WORDS: Axillary arch, Latissimus dorsi, Shoulder muscle, Axilla, Variant.

Address for Correspondence: Dr. Sushil Kumar, Assistant Professor, Anatomy division, Department of radiology, Weill Cornell Medicine, New York, USA. E-Mail: sushilbhu2001@yahoo.co.in

\section{Access this Article online}

\section{Quick Response code}

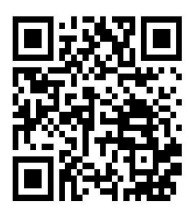

DOI: $10.16965 /$ ijar.2017.459

Web site: International Journal of Anatomy and Research

ISSN 2321-4287

www.ijmhr.org/ijar.htm

Received: 24 Sep 2017

Peer Review: 25 Sep 2017

Revised: None
Accepted: 08 Nov 2017

Published (O): 01 Dec 2017

Published (P): 01 Dec 2017

\section{INTRODUCTION}

The latissimus dorsi is a large, flat, triangular muscle that sweeps over the lumbar region and the lower thorax, and converge to a narrow tendon [1]. This muscle, covering such a large area of the back, is characterized by its wide origin and very narrow insertion. The muscle arises from the spines of the lower six thoracic vertebrae and the posterior layer of the lumber fascia, by which it is attached to the lumbar and sacral vertebral spines and to the posterior part of the crest of the ilium. Lateral to this it also arises by muscular fibers from the outer lip of the iliac crest. The upper part of the flat sheet of muscle runs horizontally, covered medially by the lower triangular part of trapezius, and passes over the inferior angle of the scapula, from which a few fibers may arise. The middle part of the muscle runs obliquely upwards and outwards. The lower part of the muscle runs vertically upwards, being reinforced by four slips from the lowest four ribs. In the axilla muscle is replaced by a flattened, shiny, white tendon, which is inserted into the floor of the intertubercular sulcus [2]. It is supplied by the thoracodorsal nerve and is active in adduction, extension and, especially in medial rotation of the humerus [1]. A rare muscular anomaly of the axilla is the axillary arch muscle also known as Langer's muscle which is a thin muscular slip extending from the latissimus dorsi to the pectoralis major. Variations of this muscular anomaly have been observed commonly as adhering to the coracoid process of the scapula, medial epicondyle of the humerus, teres major, long head of the triceps brachii, coracobrachialis or biceps brachii, and pectoralis minor. The most common form of this muscle extends from the latissimus dorsi to the pectoralis major, the short head of biceps brachii or to the coracoid process [3]. 
The neurovascular compression in the axillary region is main clinical importance of this anomaly.

\section{CASE REPORT}

During the routine dissection on about 60 yearold female cadaver in the anatomy lab of the Weill Cornell Medicine, New York, we came across an anomaly in insertion of the latissimus dorsi muscle. On the left side, a fibromuscular band extended from the lower border of the latissimus dorsi muscle to the deep surface of the pectoralis major muscle. It passes anterior to the brachial plexus, axillary artery and axillary vein. It is inserted into the deep surface of the pectoralis major muscle. Latissimus dorsi had a normal nerve supply from the thoracodorsal nerve. On the right-side insertion was normal.

Fig. 1: Showing extra slip of latissimus dorsi muscle.

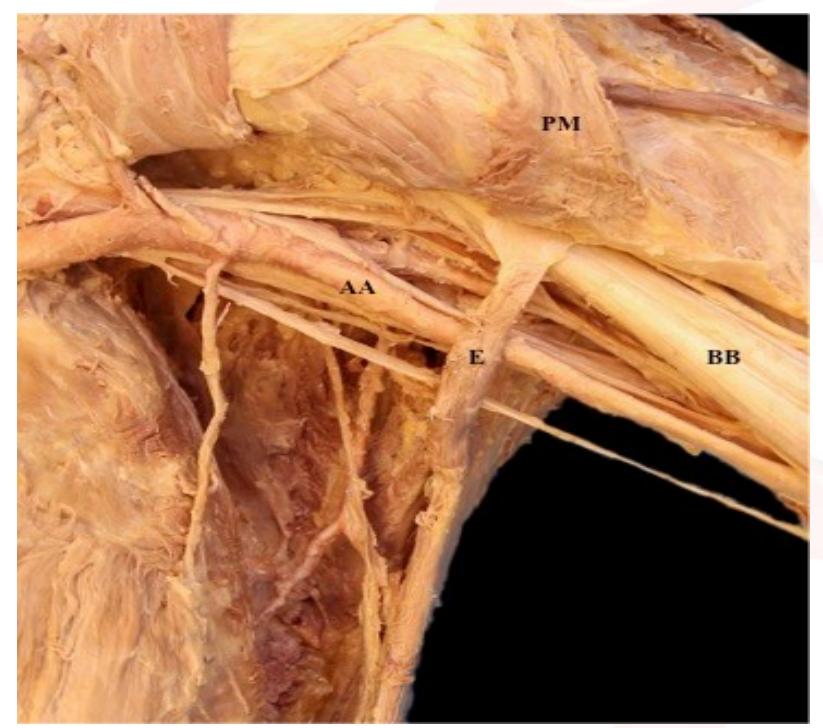

BB - Biceps brachii, PM - Pectoralis major, E - Extra slip of latissimus dorsi, AA - Axillary artery.

\section{DISCUSSION}

Variations of latissimus dorsi muscle is rare and have been reported in the anatomical, and surgical literature as variation of axillary arch muscle $[4,5,6]$.

Latissimus dorsalis is a phylogenetically ancient structure found in quadruped mammals, amphibians and reptiles (Leche 1900, Ribbing 1938). The latissimus dorsi muscle in small embryos (15-16 mm crown-rump length) appears as a narrow craniocaudal strip on the lateral side of the body extending from the eleventh rib and adjacent vertebrae to the humerus. It then spreads out in a fan shaped form in cranial and in anterocaudal directions to attain definitive positions of its attachments on vertebral spines and on the iliac crest. In the course of its development, it forms two distinct primordia, the cranial and the caudal one, each with the independent neurovascular hilum. Both these parts later fuse together, but they may be surgically separated even in the adult. In human embryos between $15 \mathrm{~mm}$ and $18 \mathrm{~mm}$ crown-rump length, a well-formed dorsoepitrochlearis primordium is visible. Later on, the arch of the muscle primordium is interrupted and disappears, probably by cell death (apoptosis).

The remaining strips of the musculus dorsoepitrochlearis detaching from the anteroinferior border of the latissimus dorsi and going to the axilla either fully disappear or remain in the form of strips known as typical muscle variants under the axillary fascia on the medial side of the brachial plexus. They can be secondarily attached to various structures in the axilla: to the capsule of the shoulder joint, to the coracoid process at its tip or its inferior surface, to the fascia of neighboring muscles, to the fascia of biceps or triceps brachii, to the crest of the greater tubercle of humerus, or into the pectoralis major as in this case.

The axillary arch muscle usually receives its nerve supply from the medial pectoral nerve, suggesting that it is derived from the pectoral muscles [7]. When closely associated with the latissimus dorsi, the axillary arch muscle can be supplied by the thoraco-dorsal nerve [8]. In our case, it appeared as the latter. The blood supply is generally from the lateral thoracic vessels. However, in our cases, we did not see a separate pedicle entering the muscle.

Arch-shaped variations in the axilla could be considered in two groups, muscular form (type I) and tendinous form (type II), accompanying different subtypes based on their nerve supplies and site of their attachment points [9]. However, clinical classification of the axillary arches could be defined as superficial and deep arch groups. Superficial group arches cross in front of the vessels and nerves, and the veins could be affected primarily within this variation that may play a role in intermittent obstruction of the axillary vein [10]. Deep group arches occur deeply on the posterior or lateral walls of the 
axilla. These arches usually cross only parts of the neurovascular bundle and axillary or radial nerves could be affected.

Clinically it has been implicated in costoclavicular compression syndrome, axillary vein entrapment, median nerve entrapment, hyperabduction syndrome, and thoracic outlet syndrome and shoulder instability syndrome [11]. This muscle can obscure palpability of axillary lymph nodes. In axillary lymph node clearance, it can obscure nodes and lead to incomplete clearance. In the case of a latissimus dorsi flap for coverage in axilla, failure to recognize this variant will result in compression of the thoraco-dorsal pedicle and subsequent loss of the flap. The superficial arch group can cause axillary vein obstruction. In the case of an inexperienced surgeon, a large muscle can baffle the surgeon and lead to unsatisfactory results. In the case of latissimus dorsi flap for coverage in axilla, failure to recognize this variant could result in compression of the thoraco-dorsal pedicle thereby resulting in loss of the flap.

\section{Conflicts of Interests: None}

\section{REFERENCES}

[1]. Standaring S, Gray's Anatomy: The Anatomical Basis of Clinical Practice. $41^{\text {st }}$ edition. Edinburg: Elsevier Churchill Livingstone, 2016; 822.

[2]. Sinnatamby C, Last's Anatomy: Regional and Applied. $12^{\text {th }}$ edition. Edinburg: Elsevier Churchill Livingstone, 2011; 77.

[3]. Loukas M, Noordeh N, Tubbs R.S, Jordan R. Variation of the axillary arch muscle with multiple insertions. Singapore Med J. 2009; 50(2): e 88-90.
[4]. Bonastre V, Rodriguez-Niedenfuhr M, Choi D, Sanudo $J R$. Coexistance of a pectoralis quadratus muscle and an unusual axillary arch; case report and review. Clin Anat. 2002; 15: 366-370.

[5]. Dharap A. An unusually medial axillary arch muscle. J Anat. 1994; 184 (Pt3):639-641.

[6]. Daniels IR, Della Rovere GQ. The axillary arch of Langer - the most common muscular variation in the axilla. Beast Cancer Res Treat. 2002; 59:77-80.

[7]. Soubhagya RN, Latha VP, Ashwin K, Madhan KS, Ganesh CK. Coexistence of an axillary arch muscle (latissimocondyloideus muscle) with an unusual axillary artery branching: Case report and review. Int J Morphol. 2006; 24:147-50.

[8]. Turgut HB, Peker T, Gülekon N, Anil A, Karaköse M. Axillopectoral muscle (Langer's muscle) Clin Anat. 2005; 18: 220-3.

[9]. Takafuji T, Igarashi J, Kanbayashi T, Yokoyama T, Moriya A, Azuma S, et al. The muscular arch of the axilla and its nerve supply in Japanese adults. Kaibogaku Zasshi. 1991;66:511-23.

[10]. Jelev L, Georgiev GP, Surchev L. Axillary arch in human: Common morphology and variety. Definition of "clinical" axillary arch and its classification. Ann Anat. 2007;189:473-81.

[11]. Mérida-Velasco JR, Rodríguez Vázquez JF, Mérida Velasco JA, Sobrado Pérez J, Jiménez Collado J. Axillary arch: Potential cause of neurovascular compression syndrome. Clin Anat. 2003;16:514-9.

How to cite this article:

Ritwik Baidya, Sushil Kumar. EXTRA SLIP OF LATISSIMUS DORSI

TENDON AND ITS CLINICAL SIGNIFICANCE. Int J Anat Res

2017;5(4.3):4733-4735. DOI: 10.16965/ijar.2017.459 